\title{
FORMAÇÃO INICIAL PÚBLICA EM EDUCAÇÃO ESPECIAL NO BRASIL: UMA ANÁLISE SOBRE OS PROJETOS POLÍTICOS PEDAGÓGICOS
}

\author{
FORMACIÓN INICIAL PÚBLICA EN EDUCACIÓN ESPECIAL EN BRASIL: UN \\ ANÁLISIS SOBRE LOS PROYECTOS POLÍTICO - PEDAGÓGICOS
}

\author{
PUBLIC INITIAL FORMATION IN SPECIAL EDUCATION IN BRAZIL: AN \\ ANAL YSIS ON PEDAGOGICAL POLITICAL PROJECTS
}

\author{
Mayara Erbes RANZAN ${ }^{1}$ \\ Marlon José Gavlik MENDES ${ }^{2}$ \\ Fátima Elisabeth DENARI ${ }^{3}$
}

RESUMO: No cenário nacional, há atualmente onze cursos de licenciatura em nível de graduação em Educação Especial, oito são de caráter particular/comunitário/filantrópico e três de origem pública. Com base nessas informações, o presente artigo buscou investigar o perfil dos cursos de licenciatura em Educação Especial oferecidos por instituições públicas de ensino superior no Brasil. Para tanto, o método abordado foi a pesquisa documental do tipo exploratória e para tratamento e a análise dos dados fez-se uso da análise por conteúdo, seguida da análise por categorias. Os resultados evidenciaram Projetos Políticos Pedagógicos estruturados e elaborados conforme as demandas dos meios que estão inseridos, porém, constatou-se ausência de princípios norteadores para a elaboração desses documentos, resultado da inexistência de diretrizes curriculares nacionais para o curso em questão. Além disso, ressalta-se que um, dos três cursos existentes, foca em deficiências específicas, não ofertando uma formação ampla e completa para o futuro profissional.

PALAVRAS-CHAVE: Formação inicial. Educação especial. Projeto político pedagógico.

RESUMEN: En el escenario nacional en el nivel de educación universitaria de pregrado, existen actualmente once carreras de licenciatura en Educación Especial, ocho son de carácter particular/comunitario/filantrópico y tres de origen público. Con base a estas informaciones, el presente artículo buscó rastrear los perfiles de esas carreras oferecidos por instituciones públicas de educación superior em Brasil. Se realizo uma investigación exploratória y documental e para el tratamento y el análisis de los datos se hizo uso del análisis por contenido, seguido del análises por categorias. Los resultados mostraron Proyectos Político-Pedagógicos estructurados y elaborados conforme a las demandas de los medios en que están insertados, sin embargo, se constató la ausencia de principios guías para la elaboración de estos

\footnotetext{
${ }^{1}$ Universidade Federal de São Carlos (UFSCAR), São Carlos - SP - Brasil. Doutoranda no Programa de PósGraduação em Educação Especial. ORCID: https://orcid.org/0000-0002-3629-5352. $\quad$ E-mail: e.r.maya@hotmail.com

${ }^{2}$ Universidade Federal de São Carlos (UFSCAR), São Carlos - SP - Brasil. Doutorando no Programa de PósGraduação em Educação Especial. ORCID: https://orcid.org/0000-0002-3473-610X. E-mail: mgmgavlik@hotmail.com

${ }^{3}$ Universidade Federal de São Carlos (UFSCAR), São Carlos - SP - Brasil. Professora Adjunta no Departamento de Psicologia e Professora no Programa de Pós-Graduação em Educação Especial. Doutorado em Metodologia do Ensino (UFSCAR). ORCID: https://orcid.org/0000-0001-9248-6359. E-mail: fadenari@terra.com.br
} 
documentos, esto por causa de la inexistencia de directrices curriculares nacionales para la carrera en cuestión. Además de esto, se resalta que, una de las tres carreras existentes, se enfoca en deficiencias específicas, sin ofrecer una formación amplia y completa para el futuro profesional.

PALABRAS CLAVE: Formación inicial. Educación especial. Proyecto político pedagógico.

ABSTRACT: In the national scenario at the undergraduate level, there are currently eleven undergraduate teaching degree courses in Special Education, eight are private/community/ philanthropic and three are of public origin. Based on this information, the present article sought to trace the profiles of these courses through the analysis of their Political Pedagogical Projects. For that, the method approached was documental research of exploratory type and for the treatment data analysis was done based on content analysis and then category analysis. The results evidenced Pedagogical Political Projects structured and elaborated according to the demands of the means that are inserted, however, it was verified that there was an absence of guiding principles for the elaboration of these documents, result of the lack of national curricular guidelines for the course in question. In addition, it is emphasized that one of the three existing courses, focuses on specific deficiencies, not offering a broad and complete formation for the future professional.

KEYWORDS: Initial formation. Special education. Pedagogical political projects.

\section{Introdução}

A implementação de políticas públicas na perspectiva da inclusão escolar tem provocado o aumento do número de alunos/as com deficiência nas escolas comuns, desafiando diretores/as, gestores/as, professores/as, entre outros, a construírem saberes e fazeres que contemplem a realidade educacional em vista da diversidade (MATOS; MENDES, 2014). Tais políticas foram elaboradas com vistas a garantir acesso, matrícula, permanência e aprendizagem destes/as alunos/as nas escolas comuns, independentemente de qualquer limitação (BRASIL, 2008).

A exemplo disso, a Política Nacional de Educação Inclusiva (Ministério da Educação e Cultura MEC-2008), dispõe sobre o Atendimento Educacional Especializado (AEE) e a resolução $n^{\circ} 4 / 2009$, institui diretrizes operacionais para este atendimento em todas as modalidades de ensino, complementando e/ou suplementando a escolarização comum, tornando necessária a ampliação do número de salas de recursos multifuncionais e, consequentemente, o investimento na formação de professores/as para atuarem nestes espaços.

Assim, intensificaram-se as formações de professores/as para o Atendimento Educacional Especializado, oferecidas pelas Instituições de Ensino Superior públicas e privadas, tanto em nível de graduação como de pós-graduação (especialização, mestrado e 
doutorado). No cenário nacional, há atualmente onze cursos de graduação na modalidade de licenciatura em Educação Especial oferecidos por oito universidades brasileiras. Deste total, oito cursos são oferecidos por seis instituições privadas, de caráter comunitário/filantrópico, e três cursos são oferecidos por duas universidades de origem pública.

A formação de professores/as para atuarem na Educação Especial é um tema que desperta interesses de pesquisadores/as da atualidade. Torres e Mendes (2018) analisaram os Projetos Políticos Pedagógicos e as diretrizes curriculares de 36 licenciaturas em Física, Química e Matemática no que tange aos temas de Educação Especial e atuação com alunos/as com deficiência. As autoras notaram que as licenciaturas ofertam ao mínimo uma disciplina voltada à Educação Especial e à inclusão, sendo que algumas também ofertavam uma disciplina de língua brasileira de sinais (LIBRAS), mas os documentos encontravam-se vagos e desatualizados em relação aos temas abordados nas disciplinas, revelando dificuldades na formação voltada para esse público.

Também discutindo a formação de licenciados para a Educação Especial, Brabo (2015) entrevistou quatro professores que ministravam disciplinas de Educação Especial em instituições federais de ensino superior. A autora constatou que a carga horaria destinada às disciplinas de Educação Especial não era suficiente para a abrangência dos temas necessários e, devido a obrigatoriedade, estas turmas eram formadas por muitos alunos/as e contavam com poucos professores/as. Além disso, a autora também averiguou pouca articulação entre as disciplinas de Educação Especial e as demais dentro dos cursos em que estavam inseridas. Devido a estes fatores, a formação tornava-se escassa. Nessa perspectiva, Borges, Santos e Costa $(2019$, p. 142) destacam que "embora haja inúmeras orientações na legislação, as pesquisas revelam que as instituições de ensino superior não têm atendido às recomendações legais".

Ao realizar um levantamento das produções bibliográficas referentes à formação de professores especializados para atuar na Educação Especial, Bueno e Marin (2011) encontraram um total de 43 estudos entre 2002 e 2008 , sendo 18 voltados à educação continuada, 12 à formação inicial e 10 abordavam ambas as formações. Os autores chamaram a atenção para a baixa produção científica sobre a formação docente e concluíram que a formação inicial de professores/as não tem sido o foco das pesquisas em Educação Especial, uma vez que essas têm se direcionado mais significativamente para formação continuada. Manzoli et al. (2020, p. 11) acrescenta que 
[...] tanto a formação inicial do professor quanto a continuada é de crucial importância para oferecerem uma educação de qualidade a todos os alunos, principalmente no que tange à educação inclusiva.

Thesing e Costas (2020), em investigação sobre a produção cientifica da Associação Nacional de Pós-Graduação e Pesquisa em Educação (ANPEd) nos anos de 2010 a 2017, averiguaram que a formação docente para a atuação na Educação Especial está entre os temas pesquisados, mas não se encontra entre os mais prevalentes. Os temas que mais se destacaram entre os anos investigados foram: políticas públicas de Educação Especial; práticas pedagógicas e inclusão; surdez; AEE e só então a formação inicial e continuada do docente.

Investigando a produção científica atual da área, nota-se que a formação específica para atuação na Educação Especial e para a inclusão de alunos/as com deficiência no ensino regular ainda é pouco explorada por pesquisadores/as brasileiros/as, o que corrobora com a colocação de Costa e Denari (2012), os quais pontuam que "se tratando do Brasil, é premente a falta de curso de formação que prepare docentes para atuarem na Educação Básica com pessoas deficientes" (COSTA; DENARI, 2012, p. 140).

Devido a isto, o objetivo deste artigo foi investigar o perfil dos cursos de licenciatura em Educação Especial oferecidos por instituições públicas de ensino superior no Brasil.

\section{Método}

Para a operacionalização da presente pesquisa, de natureza qualitativa, realizou-se uma pesquisa documental do tipo exploratória (MARCONI; LAKATOS, 1990) com o intuito de investigar os cursos de licenciatura em Educação Especial oferecidos por universidades públicas brasileira através de seus Projetos Político Pedagógicos (PPP’s).

Como critério de inclusão para definição da amostra foram consideradas apenas as instituições de ensino superior públicas cujos cursos de licenciatura em Educação Especial fossem credenciados pelo Ministério da Educação (MEC); que disponibilizassem publicamente seus documentos norteadores e diretrizes curriculares; que estivessem em atividade; fossem de modalidade presencial e em nível de graduação.

Ao fim, a amostra contou com três cursos de licenciatura em Educação Especial credenciados pelo MEC oferecidos por duas instituições públicas de ensino superior, uma localizada na região sul do país e outra na região sudeste. Os documentos analisados foram os PPP's destes cursos, os quais são de arquivo público de origem escrita, podendo ser conferidos nos endereços virtuais e oficiais das universidades. 
As informações gerais dos cursos analisados podem ser conferidas no quadro a seguir:

Quadro 1 - Informações dos cursos públicos de licenciatura em Educação Especial no Brasil ${ }^{4}$

\begin{tabular}{|l|l|l|l|}
\hline CURSO & \multicolumn{1}{|c|}{ (A) } & \multicolumn{1}{c|}{ (B) } & \multicolumn{1}{c|}{ (C) } \\
\hline NOMENCLATURA & $\begin{array}{l}\text { Curso de Licenciatura em } \\
\text { Educação Especial }\end{array}$ & $\begin{array}{l}\text { Educação Especial - } \\
\text { Licenciatura plena }\end{array}$ & $\begin{array}{l}\text { Curso de Licenciatura } \\
\text { em Educação Especial }\end{array}$ \\
\hline NÍVEL & Graduação & Graduação & Graduação \\
\hline MODALIDADE & Presencial & Presencial & Presencial \\
\hline $\begin{array}{l}\text { ÁREA DE } \\
\text { CONHECIMENTO }\end{array}$ & $\begin{array}{l}\text { Centro de Educação } \\
\text { Ciências Humanas }\end{array}$ & $\begin{array}{l}\text { Centro de Educação e } \\
\text { Ciências Humanas }\end{array}$ & $\begin{array}{l}\text { Centro de Educação e } \\
\text { Ciências Humanas }\end{array}$ \\
\hline GRAU ACADÊMICO & Licenciado & Licenciado Pleno & Licenciado \\
\hline TURNO & Integral & Integral & Noturno \\
\hline CARGA HORÁRIA & $3.315 \mathrm{~h}$ & $3.120 \mathrm{~h}$ & $3.220 \mathrm{~h}$ \\
\hline REGIME LETIVO & Semestral & Semestral & Semestral \\
\hline REGIÃO & Sudeste & Sul & Sul \\
\hline
\end{tabular}

Fonte: Elaborado pelos autores

Para tratamento e a análise dos dados fez-se uso da análise por conteúdo, seguida da análise por categorias, condizendo com os conceitos de Minayo (2002). As categorias de análise que surgiram em relação aos cursos foram: Justificativa; Objetivos; Perfil desejado do/a formando/a e Áreas de atuação; Eixos estruturantes do curso; Grade Curricular; Avaliações e Estágios.

\section{Resultados e discussão}

A primeira categoria que se destacou na análise dos PPP's dos cursos foi intitulada de 'Justificativa'. Os cursos descrevem suas justificativas baseados na necessidade de uma formação que capacite o/a profissional a trabalhar com esse público e suas especificidades, assegurando o previsto na Lei de Educação Especial na Perspectiva da Educação Inclusiva (BRASIL, 2008) e, consequentemente, contribuindo para as aquisições de conhecimento e vivências sociais que o ambiente escolar pode vir a propiciar.

Conforme exposto nos documentos, a existência dos cursos nos moldes atuais se justifica porque o contexto brasileiro atual apresenta uma enorme demanda de formação de professores/as para fazer frente a uma política educacional de inclusão escolar e atuar criticamente nos diversos campos da educação especial, como avaliação, atendimento especializado e pesquisa científica (PEIXOTO; MENDES, 2021).

${ }^{4}$ Vale ressalvar que as últimas atualizações das informações ocorreram em 2012 no curso A, 2008 no curso B e 2010 no curso $\mathrm{C}$. 
Uma vez que as necessidades educacionais especiais de alguns/mas alunos/as não desaparecem com sua mera inserção em classe comum, assim como não se elimina a necessidade de produzir conhecimento sobre a realidade desses/as alunos/as, demanda-se cursos formativos. Pletsch $(2009$, p. 145) pontua que "podemos justificar a formação em nível superior como uma das medidas essenciais a serem tomadas para que ocorram mudanças educacionais efetivas".

Na categoria intitulada 'Objetivos', as metas estabelecidas nos PPP's dos cursos foram traçadas visando uma formação profissional completa que respaldasse para a futura atuação, almejando uma formação com domínio de conteúdos, métodos, técnicas, entre outras ferramentas para, consequentemente, proporcionar a formação do seu alunado.

Além desses objetivos considerados mensuráveis, os PPP's apresentam uma série de valores que pretendem imprimir na futura formação. Valores como ética profissional, sensibilidade com as necessidades e desafios, valorização do ser humano, desenvolvimento do senso crítico, busca pela criação de novos saberes, entre outros. As metas almejadas permeiam a ideia de um perfil sensível o suficiente para se engajar no trabalho junto das pessoas com deficiência.

Vale ressaltar que os objetivos do curso B enfatizam apenas três categorias das necessidades educacionais especiais: surdez, déficit cognitivo e dificuldade da aprendizagem. A justificativa exposta no PPP para isso é de que as demais categorias de necessidades educacionais especiais abordadas serão estudadas conforme a demanda existente, em cada oportunidade por meio das disciplinas complementares da parte flexível prevista na matriz curricular.

Este fato provoca o questionamento sobre a completude da formação a se dar nesse formato, haja vista que a inclusão não se limita apenas a essas três categorias de necessidades educacionais. Segundo pesquisa realizada em Portugal por Rodrigues (2017), os cursos formadores de professores portugueses para a Educação Especial dão ênfase a algumas deficiências excluindo outras e propõem estratégias de intervenção de caráter individual e segregacionista, o que se aproxima dos moldes evidenciados no curso B. A formação docente incompleta e compartimentalizada pode contribuir para o que o autor chama de desigualdades dentro da escola, que são: "as desigualdades que podem ser atribuídas às práticas ou às estruturas da própria escola, como os professores atuam, a forma como a escola agrupa os alunos, como responde à diversidade" (RODRIGUES, 2017, p. 9). Para o autor, seria recomendado a desnaturalização das práticas escolares atuais e a formação diversificada de 
educadores/as, possibilitando práticas de ensino personalizado e adaptações curriculares para cada aluno/a.

Formar educadores/as também envolve trabalhar sobre a inclusão, tanto em seus aspectos teóricos e históricos, quanto em seus aspectos práticos. Souza (2020), em pesquisa com 243 discentes universitários do curso de Pedagogia, notou que as representações sociais de alunos/as sobre inclusão permaneceram relativamente estáticas ao longo da graduação.

Sobre os resultados da pesquisa mencionada:

Foi possível perceber que o nível conceitual entre alunos ingressantes e concluintes a respeito da inclusão é o mesmo, o que indica a falta de discussão desse tema no transcorrer do curso. Como a representação social é construída através da comunicação entre os sujeitos, presume-se que os alunos não tiveram a oportunidade de ampliar a discussão acerca dessa questão, o que impossibilitou sua ressignificação.

[...] Nesse sentido, podemos compreender que as representações sociais da inclusão são elaboradas ao partir da maneira como os indivíduos adquirem o seu conhecimento, influenciados pela quantidade expressiva de informações, valores e crenças que são acrescidas a esse conhecimento. Os alunos chegam ao curso carregados de representações sociais da inclusão, advindas do seu contexto social, essas representações são reforçadas pelos discursos presentes no meio acadêmico, o que favorece a ancoragem e sedimentação dessas representações (SOUZA, 2020, p. 1441).

Os dados encontrados por Souza (2020) mostram que a formação docente desses alunos foi suficiente em promover reflexões com maior rigor teórico e metodológico sobre inclusão, permanecendo as ideias vinculadas ao senso comum. Esse dado pode ser interessante para se levar em consideração na construção de cursos de formação docente, possibilitando buscar estratégias para contorná-lo.

Retomando a pesquisa realizada, os perfis estabelecidos nos PPP's, descritos aqui na categoria 'Perfil desejado do/ formando/a e Áreas de atuação', estão de acordo com os objetivos mostrados anteriormente. Isto é, se atingidos os objetivos lançados nos PPP's, os perfis dos/as futuros/as profissionais que trabalharão junto dos/as alunos/as com deficiência serão completos.

As três propostas dos PPP's estabelecem que os perfis dos/as formados/as em Educação Especial devem incluir competência e condições para flexibilizar sua prática de acordo com as demandas existentes, sendo capazes de executar adaptações curriculares quando necessário, desenvolver procedimentos didáticos pedagógicos e práticas alternativas adequadas a cada aluno/a para garantir a apropriação do conhecimento.

Sobre as áreas de atuação que os cursos ressaltam: 
Quadro 2 - Áreas de atuação enfatizadas em cada curso

\begin{tabular}{|c|c|c|}
\hline CURSO A & CURSO B & CURSO C \\
\hline $\begin{array}{l}\text { '...atuará na docência dos serviços de apoio } \\
\text { pedagógico especializado, nas escolas de } \\
\text { ensino regular, oferecidos na sala de recursos } \\
\text { ou multifuncionais ou classes especiais, } \\
\text { atuando de forma transversal nos diferentes } \\
\text { níveis de ensino...' } \\
\text { '...Poderá atuar em serviços de apoio } \\
\text { pedagógico especializado, nas escolas de } \\
\text { ensino regular, em parceria com os } \\
\text { professores da classe comum, sob a forma de } \\
\text { ensino colaborativo e orientações } \\
\text { pedagógicas.' } \\
\text { '...Flexibilizar e individualizar a ação } \\
\text { pedagógica nas áreas do conhecimento e } \\
\text { diferentes etapas de formação da Educação } \\
\text { Básica, Ensino Superior e da Educação de } \\
\text { Jovens e Adultos, de modo a responder às } \\
\text { necessidades específicas dos educandos...' } \\
\text { '...Atuar em equipe e em colaboração com o } \\
\text { professor do ensino regular, por meio do } \\
\text { ensino e consultoria colaborativa nas ações } \\
\text { pedagógicas, com as famílias e todos os } \\
\text { profissionais da educação e saúde envolvidos } \\
\text { com os estudantes sob sua } \\
\text { responsabilidade...” } \\
\text { '...Ensinar em diferentes ambientes de } \\
\text { aprendizagem e escolarização, incluindo } \\
\text { salas de recursos multifuncionais, classes } \\
\text { especiais, escolas especiais, classes } \\
\text { hospitalares ou em domicílios, } \\
\text { desenvolvendo práticas necessárias à } \\
\text { aprendizagem e desenvolvimento dos } \\
\text { alunos, sempre que não for possível sua } \\
\text { escolarização em classes comuns, de escolas } \\
\text { regulares...' }\end{array}$ & $\begin{array}{l}\text { '... ter competência para atuar } \\
\text { como professor de classe } \\
\text { especial, escola especial ou } \\
\text { recursos especializados, } \\
\text { desenvolvendo práticas que são } \\
\text { necessárias para aprendizagem e } \\
\text { desenvolvimento dos alunos com } \\
\text { necessidades educacionais } \\
\text { especiais, sempre que não for } \\
\text { possível sua inclusão em classe } \\
\text { regular...' } \\
\text { '...Docência em classes especiais } \\
\text { ou escolas especiais que atendam } \\
\text { alunos com dificuldades de } \\
\text { aprendizagem, déficit cognitivo } \\
\text { e surdez nas etapas da Educação } \\
\text { Infantil e dos anos iniciais do } \\
\text { Ensino Fundamental.' } \\
\text { '...Docência nos serviços de } \\
\text { apoio pedagógico especializado } \\
\text { para alunos que apresentem } \\
\text { necessidades educacionais } \\
\text { especiais nas etapas da Educação } \\
\text { Infantil e anos iniciais do Ensino } \\
\text { Fundamental, bem como nas } \\
\text { demais modalidades de } \\
\text { atendimento que permeiam essas } \\
\text { etapas: - em salas de recursos; - } \\
\text { em classes hospitalares; - em } \\
\text { ambiente domiciliar; - em } \\
\text { serviços de orientação } \\
\text { pedagógica por meio de serviço } \\
\text { itinerante; - em interpretação de } \\
\text { linguagens e códigos, como por } \\
\text { exemplo a Língua Brasileira de } \\
\text { Sinais...' }\end{array}$ & $\begin{array}{l}\text { '...docência nos serviços } \\
\text { especializados e de apoio } \\
\text { pedagógico...' } \\
\text { '...docência em classes } \\
\text { comuns da Educação } \\
\text { Infantil, Educação Básica, } \\
\text { Educação } \\
\text { Profissionalizante } \\
\text { Educação e Jovens e } \\
\text { adultos, numa perceptiva } \\
\text { de bidocência...' } \\
\text { '...docência em classes de } \\
\text { recursos ou } \\
\text { multifuncionais...' } \\
\text { '...docência em classes } \\
\text { especiais e instituições } \\
\text { especializadas...' } \\
\text { '...docência em classes } \\
\text { hospitalares.' } \\
\text { '...gestão, planejamento' } \\
\text { e orientação....” } \\
\text { pedagógica em serviços } \\
\text { de itinerância; } \\
\text { ‘..docência na modalidade } \\
\text { de ensino domiciliar....' }\end{array}$ \\
\hline
\end{tabular}

Fonte: Elaborado pelos autores

As diferenças nos campos de atuação condizem com o grau da formação, portanto conforme a Licenciatura Plena, o curso B fica restrito ao ensino infantil e anos iniciais do ensino fundamental, enquanto que os cursos A e C vão da Educação Infantil até a Educação de Jovens e Adultos.

A próxima categoria elaborada, 'Eixos estruturantes do curso', traz informações sobre a estrutura dos cursos, a qual prevê disciplinas obrigatórias e optativas de caráter teórico e prático voltadas à formação, com vistas a garantir atendimento educacional de qualidade para os/as alunos/as com deficiência. 
A matriz curricular proposta para o curso A contempla quatro eixos transversais: o primeiro eixo estruturante se refere às disciplinas de fundamentação teórica, que terão como objetivo a aquisição de conhecimentos e habilidades para compreender a natureza interdisciplinar do campo e do objeto de estudo da Educação Especial, incluindo aspectos históricos da educação e Educação Especial, políticas públicas educacionais, ética e questões do desenvolvimento humano.

O segundo eixo estruturante compreende a formação para a pesquisa, que visa o desenvolvimento pessoal e profissional do aluno/a para buscar, produzir, divulgar e saber utilizar o conhecimento científico afeto à Educação Especial.

O terceiro eixo é a aprendizagem fundamentada na indissociabilidade entre teoria e prática, a fim de garantir a transversalidade deste tipo de formação.

No quarto e último eixo transversal de formação o foco é a prática, por meio de atividades de estágio supervisionado a serem cumpridas em situações reais de trabalho.

O curso B também divide o seu PPP em quatro eixos, sendo o primeiro o eixo didático pedagógico, o segundo eixo é da fundamentação da Educação Especial, o terceiro eixo das categorias específicas dessa formação, como dificuldades de aprendizagem, déficit cognitivo e surdez, e o por último o eixo dos estágios supervisionados.

Já o curso C divide o seu PPP em apenas três eixos, sendo o primeiro o eixo da Educação e Educação Especial: fundamentos em ação. O segundo eixo é o de Contextos e Prática na Educação Especial, que organiza o bloco de formação na especificidade do trabalho profissional. Esse eixo leva em consideração o estudo, a avaliação de desenvolvimento e aprendizagem e a proposição de práticas educativas com os diferentes sujeitos e linhas de atuação. E o último eixo, é o de Pesquisa Profissional e Estágio, que estrutura o último ano do curso, tendo em vista o projeto e desenvolvimento de uma pesquisa em uma das linhas de atuação, sendo esse também, foco da observação, planejamento, desenvolvimento e avaliação da atuação profissional através do estágio/prática supervisionada.

Para Puhl (2016), a formação profissional no ensino superior ocorre na relação intrínseca entre ensino, pesquisa e extensão, a qual exprime a transmissão de conhecimentos já produzidos, a produção de novos conhecimentos e a aplicação deste em contextos práticos. Junto com a relação entre teoria e prática, a tríade ensino, pesquisa e extensão também busca o avanço da ciência com a descoberta de novos conhecimentos e o retorno da produção cientifica universitária para a comunidade em que ela está inserida, tanto pela extensão quanto pelos estágios. É notável esta preocupação nos cursos analisados, os três cursos buscam, além da transmissão dos conhecimentos, a produção de novos conhecimentos via pesquisa cientifica e 
a aplicação destes pelos estágios, mas estes dois aspectos ficam limitados apenas ao último ano da graduação nos cursos $\mathrm{B}$ e $\mathrm{C}$ e aos dois últimos anos no curso $\mathrm{A}$.

Os eixos e seus componentes formam as matrizes curriculares, delineadas na categoria 'Grade curricular'. Os PPP's detalham as disciplinas dispostas em cada um dos eixos já descritos, além dos estágios e outras subdivisões que complementam a formação. No quadro 3 a seguir está exposto um breve resumo de cada componente identificado nas grades curriculares dos PPP's analisados e suas respectivas cargas horárias.

Quadro 3 - Cargas horárias dos componentes das grades curriculares

\begin{tabular}{|l|c|c|c|}
\hline & CURSO A & CURSO B & CURSO C \\
\hline Disciplinas Obrigatórias & $2.220 \mathrm{hs}$ & $2.235 \mathrm{hs}$ & $2.535 \mathrm{hs}$ \\
\hline Disciplinas Optativas & $180 \mathrm{hs}$ & $210 \mathrm{hs}$ & $120 \mathrm{hs}$ \\
\hline Estágios & $525 \mathrm{hs}$ & $450 \mathrm{hs}$ & $405 \mathrm{hs}$ \\
\hline Trabalho de Conclusão de Curso & $180 \mathrm{hs}$ & $60 \mathrm{hs}$ & $150 \mathrm{hs}$ \\
\hline Horas Extras curriculares & $210 \mathrm{hs}$ & $165 \mathrm{hs}$ & $160 \mathrm{hs}$ \\
\hline TOTAL & $3.315 \mathrm{hs}$ & $3.120 \mathrm{hs}$ & $3.220 \mathrm{hs}$ \\
\hline
\end{tabular}

Fonte: Elaborado pelos autores

De acordo com os dados ilustrados no quadro 3, as cargas horárias de cada um dos componentes dos PPP's se assemelham entre si, não evidenciando grandes discrepâncias nas horas investidas em cada uma das atividades nos diferentes cursos. De modo geral, os dados encontram-se em consonância com a Resolução do Conselho Nacional de Educação/Conselho Pleno 2, de 19 de fevereiro de 2002 que institui a duração e a carga horária dos cursos de licenciatura, de graduação plena, de formação de professores da Educação Básica em nível superior:

Art. $1^{\circ}$ A carga horária dos cursos de Formação de Professores da Educação Básica, em nível superior, em curso de licenciatura, de graduação plena, será efetivada mediante a integralização de, no mínimo, 2800 (duas mil e oitocentas) horas, nas quais a articulação teoria-prática garanta, nos termos dos seus projetos pedagógicos, as seguintes dimensões dos componentes comuns: I - 400 (quatrocentas) horas de prática como componente curricular, vivenciadas ao longo do curso; II - 400 (quatrocentas) horas de estágio curricular supervisionado a partir do início da segunda metade do curso; III 1800 (mil e oitocentas) horas de aulas para os conteúdos curriculares de natureza científico cultural; IV - 200 (duzentas) horas para outras formas de atividades acadêmico-científico-culturais (BRASIL, 2002, p. 16). 
Entretanto é necessário destacar que os cursos B e C deixam a desejar no que compete às duzentas horas para outras formas de atividades acadêmico-científico-culturais (horas extras curriculares), ofertando parcialmente a carga horária destinada a essas atividades.

A avaliação na universidade deve ser considerada como uma atividade essencial para o aperfeiçoamento acadêmico, a melhoria da gestão universitária e a prestação de contas à sociedade, que é, em última análise quem a financia. De acordo com Luckesi (2005), o processo avaliativo da aprendizagem educacional objetiva auxiliar o/a aluno/a no seu processo de ensino e aprendizagem, e prestar informações à sociedade sobre a qualidade do trabalho educativo realizado.

Nesta perspectiva, a categoria chamada de 'Avaliações' traz informações sobre o processo avaliativo nos cursos de licenciatura em Educação Especial. O curso A define sua avaliação como uma avaliação processual. De acordo com a descrição analisada no PPP, esse tipo de avaliação é compatível com práticas pedagógicas sustentadas na interação, na multiplicidade de conhecimentos a serem abordados e na diversidade de aspectos da realidade social a serem considerados, bem como com preponderância dos aspectos qualitativos sobre os quantitativos. Já os cursos B e C denominam a sua avaliação como uma avaliação emancipatória, ou seja, aquela que requer reflexão tanto sobre a prática quanto aos efeitos da avaliação.

Além das avaliações do desempenho dos/as acadêmicos/as, os cursos se propõem a avaliar as condições dispostas em ambiente, recursos, corpo docente para que a avaliação seja completa e atinja seus objetivos. Há documentos que oficializam as notas de forma quantitativa para os devidos fins, porém, a preocupação enfatizada nos PPP's é de que a avaliação seja instrumento complementar de conhecimento, que seja utilizado como um processo e não como classificador. Em resumo, o ato de avaliar descrito nos PPP's serve como ferramenta para verificar o aprendizado e as condições dispostas ao mesmo.

Os estágios presentes nos cursos trazidos em categoria de mesmo nome, oferecem aos/as acadêmicos/as um conhecimento da situação de trabalho, isto é, diretamente em unidades escolares dos sistemas de ensino. Caracteriza-se como momento para vivenciar a prática profissional focalizando a regência, serviços de apoio educacional especializado, acompanhamento de aspectos da vida escolar, tais como elaboração do Projeto Pedagógico, da matrícula, da organização das turmas, a gestão escolar, e do tempo e espaço escolares. Consiste em um processo planejado, visando a integração entre conhecimento práticos e teóricos que complementam a formação acadêmica. 
O formato disposto para os estágios também vai ao encontro com as propostas e objetivos de cada curso. Por esse motivo, o curso B tem como obrigatórios os estágios das três áreas de concentração: surdez, déficit cognitivo e dificuldade da aprendizagem, com total de 150 hs cada. Por conta de a formação ser voltada para a licenciatura plena, presume-se que os estágios também se restrinjam ao ensino infantil e anos iniciais do ensino fundamental, não constando essa informação no PPP.

Como definido no PPP do curso A, o/a acadêmico/a deverá cumprir o estágio obrigatório no mínimo de um semestre em instituição de ensino especializado e o mínimo de dois semestres em escolas de ensino regular, distribuídos obrigatoriamente em duas etapas a escolher, educação infantil, ensino fundamental, ensino médio ou educação de jovens e adultos. Somamse ao total dessas atividades $405 \mathrm{hs}$.

O estágio do curso C é dividido em duas etapas, Estágio Supervisionado I - Observação e Proposta e Estágio Supervisionado II - Prática Pedagógica e Relatório com cargas horárias de 135 hs e 270 hs respectivamente. Porém, não estão disponibilizados no PPP os formatos que esses estágios devem ser executados, o que leva a questionar a configuração dos estágios no que envolve uniformidade e consistência da formação.

\section{Considerações finais}

Os Projetos Políticos Pedagógicos são documentos de extrema importância que possibilitam direcionamentos para os cursos de licenciatura em Educação Especial, traçando um caminho a ser percorrido, além de esclarecer fatores importantes e assegurar valores para uma formação de qualidade. De modo geral, são projetos criteriosamente estruturados e que, se cumpridos da forma como foram redigidos, formarão profissionais completos e capazes de contribuir para a equidade em solo escolar. Os PPP's analisados evidenciam a necessidade e importância da existência de cursos de formação docente em Educação Especial no cenário nacional.

Porém, é necessário destacar duas ressalvas. A primeira condiz com a especificação na formação de um dos três cursos, o que implica em uma formação não tão completa como as demais. A segunda está relacionada com as diretrizes balizadoras dos PPP's. Os Projetos Político Pedagógicos dos cursos analisados tomam como referência as diretrizes nacionais específicas para o Ensino Superior, mas faltam orientações e diretrizes curriculares nacionais específicas sobre o curso de Educação Especial na modalidade de licenciatura. De um lado, tal condição pode sugerir uma decisão mais tímida em razão da recenticidade desses cursos, no 
cenário das instituições de ensino superior, o que colabora para a diversidade de concepções e formas de organização curricular que emergiram a partir de cada curso analisado. De outro lado, pode-se pressupor que tal fato resulta na elaboração de PPP's individualizados, que emergem conforme as demandas regionais e acarretam diversas perspectivas de formação.

Portanto, para que o curso de Educação Especial se fortaleça e forme profissionais com conteúdo consolidado a partir dos mesmos princípios e bases é imprescindível a criação de diretrizes curriculares nacionais, ainda que mínimas, que permitam nortear a formulação de Projetos políticos pedagógicos para os cursos de licenciatura em Educação Especial. Porém, ainda que esses princípios possam vir a se tornar realidade, não se pode perder de vista, a extensão do território brasileiro e suas regionalidades. Espera-se que esta pesquisa possa contribuir para esta demanda e para a formação docente na área da Educação Especial.

AGRADECIMENTOS: Coordenação de Aperfeiçoamento de Pessoal de Nível Superior (CAPES)

\section{REFERÊNCIAS}

BORGES, W. F.; SANTOS, C. S.; COSTA, M. P. R. Educação Especial e formação de professores: uma análise dos projetos pedagógicos de curso (PPC). Revista IberoAmericana de Estudos em Educação, Araraquara, v. 14, n. 1, jan./mar. 2019. Disponível em: https://periodicos.fclar.unesp.br/iberoamericana/article/view/11267/7883. Acesso em: 31 jul. 2020.

BRABO, G. M. B. A formação docente inicial na perspectiva da educação inclusiva: com a palavra, o professor formador. In: REUNIÃO NACIONAL DA ANPED, 37., 2015, Florianópolis. Anais [...]. Florianópolis, SC: UFSC, 2015. Disponível em: http://www.anped.org.br/sites/default/files/trabalho-gt15-4552.pdf. Acesso em: 9 jul. 2020.

BRASIL, Ministério da Educação. Secretaria da Educação Especial. Diretrizes Nacionais para a Educação Especial na Educação Básica. Brasília, DF: MEC, SEESP, 2001.

BRASIL. Parecer CNE/CP 9, de 08 de maio de 2001. Diretrizes Curriculares Nacionais para a Formação de Professores da Educação Básica. Nível Superior, curso de licenciatura, de graduação plena. Brasília, DF: MEC, 2002. Disponível em:

http://portal.mec.gov.br/cne/arquivos/pdf/009.pdf. Acesso em: 9 jul. 2020.

BRASIL. CNE. Resolução CNE/CP 2, de 19 de fevereiro de 2002. Institui a duração e a carga horária dos cursos de licenciatura, de graduação plena, de formação de professores da Educação Básica em nível superior. Brasília, DF, 4 mar. 2002. Disponível em: http://portal.mec.gov.br/cne/arquivos/pdf/CP022002.pdf. Acesso em: 9 jul. 2020. 
BRASIL. Ministério da Educação. Diretrizes do Programa do Governo Federal de Apoio a Planos de Reestruturação e Expansão das Universidades Federais Brasileiras - REUNI. Brasília, DF: MEC, 2007.

BRASIL, Ministério da Educação. Política Nacional de Educação Especial na perspectiva da Educação Inclusiva. Brasília, DF, 2008. Disponível em:

http://peei.mec.gov.br/arquivos/politica_nacional_educacao_especial.pdf. Acesso em: 10 ago. 2018.

BRASIL. Ministério da Educação. Secretaria de Educação Básica. Diretrizes Curriculares Nacionais Gerais da Educação Básica. Brasília, DF: MEC, SEB, 2013.

BRASIL. Resolução CNE/CEB 4, de 2 de outubro de 2009. Institui Diretrizes Operacionais para o Atendimento Educacional Especializado na Educação Básica, modalidade Educação Especial. Brasília, DF, 5 out. 2009. Disponível em:

http://portal.mec.gov.br/dmdocuments/rceb004_09.pdf. Acesso em: 9 jul. 2020.

BUENO, J. G. S.; MARIN, A. J. Crianças com necessidades educativas especiais, a política educacional e a formação de professores: generalistas ou especialistas. In: CAIADO, K. R. M.; JESUS, D. M.; BAPTISTA, C. R. (Org.). Professores e educação especial: formação em foco. Porto Alegre, RS: Mediação, 2011. p. 111-130.

COSTA, V. B.; DENARI, F. E. Formação docente: reflexões sobre a escolarização dos estudantes com deficiência no ensino comum. Revista Ibero-Americana de Estudos em Educação, Araraquara, v. 7, n· 1. 2012. Disponível em:

https://periodicos.fclar.unesp.br/iberoamericana/article/view/5374. Acesso em: 31 jul. 2020.

LUCKESI, C. C. Avaliação da aprendizagem escolar. 17. ed. São Paulo, SP: Cortez, 2005.

MANZOLI, L. P.; BATISTA, B. R.; SANTOS, C. V. A prática pedagógica no atendimento educacional especializado para o aluno com deficiência intelectual. Revista Ibero-

Americana de Estudos em Educação, Araraquara, v. 15, n. 3, p. 1250-1264, jul./set. 2020. e-ISSN: 1982-5587. Disponível em:

https://periodicos.fclar.unesp.br/iberoamericana/article/view/12965. Acesso em: 31 jul. 2021.

MARCONI, M. A.; LAKATOS, E. M. Técnicas de pesquisa. São Paulo, SP: Atlas, 1990. p. 56-123.

MATOS, S. N.; MENDES, E. G. Demandas decorrentes da Inclusão Escolar. Revista Educação Especial, Santa Maria (RS), v. 27, n. 48, jan./abr. 2014. Disponível em: https://periodicos.ufsm.br/educacaoespecial/article/view/8796. Acesso em: 23 abr. 2020.

MINAYO, M. C. S. Pesquisa social: teoria, método e criatividade. Petrópolis, RJ: Editora Vozes, 2002. p. 74-76.

PEIXOTO, J. C. G; MENDES, O. M. Avaliação escolar e as crianças com deficiências: de políticas excludentes a aproximações inclusivas. Revista on line de Política e Gestão Educacional, Araraquara, v. 25, n 1, p. 06-18, jan./abr. 2021. e-ISSN: 1519-9029. Disponível em: https://periodicos.fclar.unesp.br/rpge/article/view/14113. Acesso em: 31 jul. 2021. 
PLETSCH, M. D. A formação de professores para a educação inclusiva: legislação, diretrizes políticas e resultados de pesquisas. Educar em Revista, Curitiba, n. 33, p. 143-156, 2009. Disponível em: https://revistas.ufpr.br/educar/article/view/5233. Acesso em: 14 jul. 2020.

PUHL, M. J. O conhecimento e o princípio da indissociabilidade entre ensino, pesquisa e extensão. Revista HISTEDBR On-line, Campinas, v. 16, n. 69, set. 2016. Disponível em: https://periodicos.sbu.unicamp.br/ojs/index.php/histedbr/article/view/8645281. Acesso em: 13 jul. 2020.

RODRIGUES, D. Os desafios da equidade e da inclusão na formação de professores. Revista de Educación Inclusiva, v. 7, n. 2, 2017.

SAVIANI, D. Formação de professores: aspectos históricos e teóricos do problema no contexto brasileiro. Revista Brasileira de Educação, Rio de Janeiro, v. 14, n. 40, p. 143-155, jan./abr. 2009. Disponível em: https://www.scielo.br/pdf/rbedu/v14n40/v14n40a12.pdf. Acesso em: 10 mar. 2020.

SAVIANI, D.; DUARTE, N. A Formação humana na perspectiva histórico-ontológica. Revista Brasileira de Educação, Rio de Janeiro, v. 15, n. 45, p. 422-590, set./dez. 2010. Disponível em: https://www.redalyc.org/articulo.oa?id=27515491002. Acesso em: 10 mar. de 2020.

SOUZA, S. C. M. A representação social da inclusão na formação de professores. Revista on line de Política e Gestão Educacional, Araraquara, v. 24, n. 3, p. 1420-1444, set/dez. 2020. e-ISSN: 1519-9029. Disponível em: https://periodicos.fclar.unesp.br/rpge/article/view/13603. Acesso em: 10 mar. 2021.

THESING, M. L. C.; COSTAS, F. A. T. As pesquisas em Educação Especial na ANPEd: a produção do conhecimento nas reuniões científicas nacionais. Revista IberoAmericana de Estudos em Educação, Araraquara, v. 15, n. 3, p. 1146-1166, jul./set. 2020. eISSN: 19825587. Disponível em: https://periodicos.fclar.unesp.br/iberoamericana/article/view/12426. Acesso em: 10 mar. 2021.

TORRES, J. P.; MENDES, E. G. Formação de professores de ciências exatas numa perspectiva inclusiva. Revista Insignare Scientia-RIS, Cerro Largo, v. 1, n. 3, 2018. Disponível em: https://periodicos.uffs.edu.br/index.php/RIS/article/view/10596. Acesso em: 09 jul. 2020.

UNIVERSIDADE FEDERAL DE SANTA MARIA. Projeto Político Pedagógico do curso de licenciatura plena em Educação Especial. Santa Maria, RS: UFSM, 2008. Disponível em: http://w3.ufsm.br/edespecial/?page_id=101. Acesso em: 3 abr. 2020.

UNIVERSIDADE FEDERAL DE SANTA MARIA. Projeto Político Pedagógico do curso de licenciatura noturno em Educação Especial. Santa Maria, RS: UFSM, 2010. Disponível em: http://eespecialnoturno.blogspot.com//. Acesso em: 3 abr. 2020.

UNIVERSIDADE FEDERAL DE SÃO CARLOS. Projeto político pedagógico do curso de licenciatura em educação especial. São Carlos, SP: UFSCar, 2012. Disponível em: www.prograd.ufscar.br/cursos/cursos-oferecidos-1/educacao-especial/educacao-especialprojeto-pedagogico.pdf. Acesso em: 3 abr. 2020. 


\section{Como referenciar este artigo}

RANZAN, M. E.; MENDES, M. J. G.; DENARI, F. E. Formação inicial pública em educação especial no Brasil: uma análise sobre os projetos políticos pedagógicos. Revista on line de Política e Gestão Educacional, Araraquara, v. 25, n. 2, p. 1135-1150, maio/ago. 2021. eISSN:1519-9029. DOI: https://doi.org/10.22633/rpge.v25i2.15192

Submetido em: $11 / 06 / 2021$

Aprovado em: 15/07/2021

Publicado em: 01/08/2021 